Chelonian Conservation and Biology, 2012, 11(2): 268-272 (C) 2012 Chelonian Research Foundation

\title{
First Report of Turtles from the Himalayan Kingdom of Bhutan
}

\author{
Jigme Tshelthrim Wangyal ${ }^{1}$, \\ DorJi WangChuK ${ }^{2}$, AND INDRANeIL DAs ${ }^{3}$ \\ ${ }^{1}$ College of Natural Resources, Royal University of Bhutan, Lobesa, \\ Punakha, Bhutan [jigmewangyal@gmail.com]; \\ ${ }^{2}$ Royal Manas National Park, Gelephu, Sarpang, Bhutan \\ [d_wanggele@yahoo.com]; \\ ${ }^{3}$ Institute of Biodiversity and Environmental Conservation, \\ Universiti Malaysia Sarawak, 94300, Kota Samarahan, Sarawak, \\ Malaysia [idas@ibec.unimas.my]
}

Abstract. - Five turtle species, Cuora amboinensis, C. mouhotii, Cyclemys gemeli, Melanochelys tricarinata, and Indotestudo elongata, are reported for the first time from the Himalayan Kingdom of Bhutan. The record of $C$. mouhotii represents a significant range extension to the west; that of $C$. amboinensis represents a range extension across a political border from the same landscape in adjacent Northeast India; and those of C. gemeli, M. tricarinata, and I. elongata fill geographic gaps in their known distributions. An analysis of distributions of other turtle species in adjacent eastern Nepal and Northeast India suggests that additional country records of turtles may be found in Bhutan, especially in the southern lowlands of the country.

Bhutan is a mountainous, landlocked Himalayan country, lying between the two large Asian nations of China and India, on the southern slopes of the Himalayas (Fig. 1). Consequently, it was generally assumed that the country is of low priority in terms of turtle conservation, and indeed, no turtle species has been reported during previous herpetological surveys (e.g., Biswas 1976; Bauer and Günther 1992; Das and Palden 2000; Wangyal 2011). Here we report the occurrence of five turtle species in the Himalayan Kingdom of Bhutan. One of these represents a significant range extension to the west, one represents a range extension across a political border from the same landscape in adjacent Northeast India, and three fill geographic gaps in their known global distributions.

For each of these records, we provide a digital voucher, georeferenced locality data within each relevant Dzongkhag (= district), a habitat description, and information on previously known species range. We are convinced that these records refer to naturally occurring, wild individuals (and not human-transported individuals), as they were observed in protected areas within undisturbed broadleaved forests with low human densities. As further evidence, there are no reports of turtle trade or consumption within Bhutan that we are 